\title{
Mapping Kuwait bathymetry using passive multispectral remote sensing
}

\author{
Jasem A Albanai \\ ${ }^{1}$ Marine Monitoring Section, Water Quality Monitoring Department, Environmental Public \\ Authority, Kuwait \\ ${ }^{2}$ Dept. of Geography, College of Graduate Studies at Kuwait University, Kuwait \\ Corresponding author: Albanay.com@gmail.com
}

\begin{abstract}
Mapping bathymetry is essential for many fields, including science, engineering, and the military, among others. Bathymetry is extremely important in the scientific field because it is linked to many physical and environmental issues such as coastal erosion, sea-level rise, and water quality. Traditionally, conventional methods, such as pre-measured cable passage, were used to estimate depths. Lately, echo-sounder assessments were used on hydrograph ships. This method is effective, but it is very costly in both economic and time terms. Remote sensing technology provides modern methods for mapping bathymetry, such as the use of active and passive remote sensing. Many satellite sensors cover multispectral bands. Some are commercial, such as IKONOS and WorldView, while others are freely available, such as Landsat 8 and Sentinel-2. In this study, Landsat 8 (15 meters spatial resolution) was used to estimate the depths of the waters of Kuwait, an Arabian Gulf country located on the Northwestern side of the gulf. Ground truthing points (GTPs) were used to build a bathymetric model of Kuwaiti territorial water (KTW) using the ratio transform algorithm (RTA) applied on Landsat 8 data. The results showed a good ability of Landsat 8 and RTA to estimate the depths of Kuwait's waters, where the relationship between the derived model from Landsat 8 and the GTPs was positive $\left(r^{2}=0.9634\right)$. Meanwhile, the accuracy of the derived bathymetric model was evaluated by computing the Root Mean Square Error (RMSE $= \pm 1.66$ meters) and Mean Absolute Error $(\mathrm{MAE} \pm=1.29)$.
\end{abstract}

Keywords: Bathymetry; GIS Science; Kuwait; multispectral remote sensing; ratio transform algorithm.

\section{Introduction}

The hydrosphere covers about $71 \%$ of the Earth's total area., which renders it very important in scientific fields. Since the beginnings of the information revolution, remote sensing methods have become one of the most valuable tools to understand the seas and oceans. Through space measurements and remote sensing technology, it is possible to estimate many variables related to the hydrosphere. One of the variables that can be estimated from remote sensing is bathymetry.

Bathymetry is extremely important in topics related to coastal zone management, sea-level rise, navigation, planning, engineering, fishing, oil drilling, hydrodynamics, and water quality assessment. The number and relative importance of these fields drive the need for an accurate bathymetric database. Traditionally, conventional methods were used to estimate depths, such as pre-measured cable passage being placed on ships and allowed to reach the seafloor. This method can detect the depths as single separated points that could be used to eliminate counters maps (Pushparaj \& Hegde, 2017). Lately, more advanced methods have been adopted, such as using single or multibeam echo-sounder assessment to hydrograph 
ships (Figure 1), where the time that the sound waves take to reach the seabed and return to the ship is used to determine depths. This method can work accurately in clear waters, though it is limited in murky waters, due to the infiltration of sound waves (Jagalingam et al., 2015). It is estimated that this method would take around 200 years of field survey to map the Earth's seas and oceans (Carron et al., 2001).

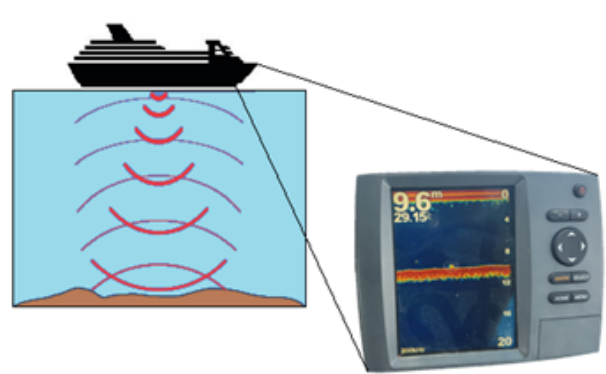

Fig. 1. Using the hydrograph carrying an eco-sounder to detect seawater depths through field survey depending on sound waves. This was a preliminary procedure to find out the applicability of the model to Kuwait seawater.

Recently, remote sensing technology provides many methods to estimate depths, such as Radar and LIDAR, etc. These methods are useful, but their high cost and unavailability in some regions make their applications limited. However, other methods have recently been developed to estimate depths. One of these methods depends on optical remote sensing data. The principles of estimating water columns using optical remote sensing are based on multispectral visible bands (light). Generally, solar radiation, which interacts with the atmosphere, is reflected by the seafloor depending on its spectral behavior; this can be detected by satellite sensors to determine depths. The penetration of light depends on water conditions such as water quality, turbidity, colour, transparency (Gao, 2009). The scattering and absorption of the light by sedimentary particles, dissolved organics, and material affect the maximum depth at which the technique can work. However, this method remains an opportunity to estimate depths in near-coastal areas with shallow and clear water. The use of multispectral remote sensing in bathymetric mapping has been developed by a range of literature (Lyzenga et al., 2006; Lyzenga, 1978, 1985; Philpot, 1998; Stumpf \& Holderied, 2003). This method is distinguished by its applicability to multispectral images that are available freely, such as those from Landsat 8 and Sentinel-2. Generally, Field surveys and ground-truthing points are important for remote sensing measurements (Al Jassar \& Rao, 2015).

Much literature displays bathymetric maps of the Arabian Gulf using different methods with a different spatial resolution range (Al-salem et al., 2018; Evagorou et al., 2019; Jagalingam et al., 2015; Karbassi et al., 2017; Pushparaj \& Hegde, 2017; Rezaeilatifi, 2015). At the local level of the State of Kuwait, the Ministry of Transportation first mapped the bathymetry of Kuwait water in 1986 and subsequently updated it in 1999. The Ministry of Defence also did the same in the 1990s. This study aims to build a new bathymetric model of Kuwait territorial waters based on remote sensing instruments.

\section{Material \& methodology}

\subsection{Study area}

Kuwait's territorial water is located in the north of the Arabian Gulf, specifically between Saudi Arabia, Iraq, and Iran (Figure 2). The water of the Arabian Gulf is characterized by shallow depths, with an average of about 35 meters and a maximum of roughly over 100 meters in the far south of the gulf. However, because of the region's high temperatures, sea surface temperature and salinity concentration are relativity high (Alyamani et al., 2004).

It is estimated that the area of Kuwait's territorial waters is around $8000 \mathrm{~km} 2$, and it has a perimeter of about $1000 \mathrm{~km}$. The northern water of the State of Kuwait is characterized by abundant sediments due to the location in the south area of Shat Al-Arab 
(the delta of the Tigris and Euphrates rivers). As for the southern waters, they are clearer and deeper. In the middle of Kuwaiti waters, there is a shallow and highly bioconcentrated gulf, locally called Kuwait Bay (El-Baz \& Al-Sarawi, 2000). Kuwait has nine islands in its territorial waters.

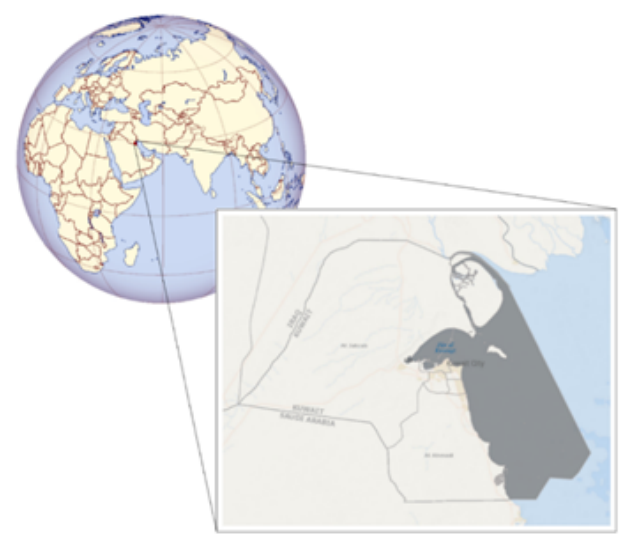

Fig. 2. The territorial waters of the State of Kuwait.

\subsection{Data description}

Two Landsat 8 images, taken on 6 July 2019, were downloaded freely from the USGS website (USGS, 2020) on 7 September 2019. Landsat 8 data is important due to its freely available nature, with images taken two times a month with a moderate spatial resolution to 15 meters, and a spectral resolution of 11 bands covering spectral channels from early blue to near-infrared and thermal bands. In addition to the wide range that the single plate covers, the chief reasons for choosing Landsat 8 are the availability and the spectral and spatial resolutions. The image date chosen was due to the appropriate weather conditions.

Depth ground-truthing points $(\mathrm{n}=841)$ were obtained from eMISK (Environment Public Authority, 2020) refereed to the Ministry of Communication (moc.gov. kw) and Ministry of Defence (different scales). These points were used to calibrate the derived model from Landsat 8 and to evaluate the final model, where they were divided into two groups.

\subsection{Data pre-processing}

For satellite images, the two Landsat 8 images were radiometrically calibrated. Radiometric calibration is a process used to convert the pixel values from digital numbers, a primary form of satellite images, to radiance which can find one stand of pixels values. Then, the images were enhancement spatially and spectrally using pan-sharping. This technique was applied to increase the spatial resolution of the multispectral bands using the panchromatic band. This image has a spatial resolution of 15 meters, while the multispectral band is 30 meters (Albanai, 2019; Albanai, 2020). Then, the images were merged using the seamless mosaic technique (resampling method: nearest neighbor) to cover the study area. In addition, low pass filtering was applied to the merged image to decrease the speckle noise using a convolution function with the following formula:

$$
L P F=\ln t \frac{\frac{1}{n} \sum_{i=1} c_{i} v_{t}}{n}
$$

Where LPF is a low pass filter. $c_{i}$ refers to the convolution mask (kemel size: 3 pixels), $\mathrm{v}_{\mathrm{i}}$ to convolution values.

All these steps were applied using ENVI 5.3 software. Following that, the image was pre-processed and ready for analysis and matching with the ground-truthing points. These points were exported as a shapefile and corrected geometrically to the zonal projected coordinate system at WGS_1984_ UTM_Zone_39N using ArcGIS 10.7.1.

\subsection{Spatial statistical analysis}

To extract the water body and separate it from the land, the near-infrared (NIR) band of Landsat 8 was used, where this band's characteristic is high land reflectance and low water reflectance (Figure 3). Naturally, 
this can be used to delineate the water body from the land (Frazier et al., 2000). Map algebra tool in ArcGIS 10.7 software has been used to create a vector layer for Kuwait seawater. After extracting the water body, the Environmental Public Authority map (Environment Public Authority, 2020) was used to determine Kuwait's marine boundary and subset the Kuwaiti territorial water. The last two steps were to find a final Kuwait waterbody vector layer.

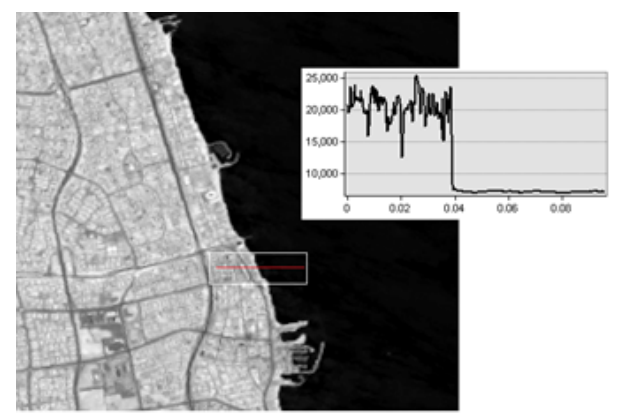

Fig. 3. The spectral behavior of water differs from that of land (Near Infrared band "NIR"); this could be used to map the shoreline and separate land from the sea.

A ratio transformation algorithm (RTA) was applied to the image. The algorithm makes use of two spectral bands, where the blue band was divided into the green band. The blue band can reach around $>30$ meters depth, and can also estimate the depths in turbid water, where the green is stronger in the coastal environment (Jagalingam et al., 2015). The ratio between the two bands could be used to estimate depths. This formula was applied earlier by Stumpf \& Holderied (2003). The following formula was used to estimate Kuwait's water depths:

$$
Z=m_{1}\left(\frac{\ln \left(L_{o b s}\left(\text { band }_{i}\right)\right)}{\ln \left(L_{\text {obs }}\left(\text { band }_{j}\right)\right)}\right)-m_{0}
$$

Where $\mathrm{Z}$ is the estimated depth. $\mathrm{L}_{\mathrm{obs}}$ is the radiance of optical bands, $i$ refers to the blue band and $\mathrm{j}$ refers to the green band. $m_{1}$ is offset and $m_{0}$ is gain, which is determined empirically.

Ground truthing points $(\mathrm{n}=841)$ were used to match the derived model from Landsat 8 after applying RTA, and to evaluate the final bathymetric model derived from regression analysis. The location of points was chosen randomly in both shallow and deep water (Figure 4). The whole body of water was analyzed, except the northern region of Kuwait water (around Bubyan Island) which was avoided due to the high sediment concentration; the abnormally high reflection pixel values suggest the presence of some passing oil tankers or outliers at the time of capture. The GTPs were then separated into two groups, where GTPs $(n=519)$ were matched to the derived model from Landsat 8 after applying RTA using Arc toolbox on ArcGIS 10.7.1. Every truthing point value was compared to the pixel value with the same geographical coordinate. Following that, the image was calibrated using a regression algorithm. The result is a raster layer containing depth values with 15 meters spatial resolution.

To assess the accuracy of the derived model, RMSE and MAE were computed. Ground truthing points $(n=322)$ were used. The RMSE and MAE are statistical indices used to evaluate and estimate the accuracy between variables. The indices were computed after applying the regression algorithm to the derived model from the satellite image, where the GTPs were matched to the derived model from Landsat 8 after applying RTA. The following formulas were used to estimate RMSE and MAE respectively:

$$
\begin{aligned}
R M S E & = \pm \sqrt{\frac{1}{n} \sum_{i=1}\left(x_{i}-x_{j}\right)^{2}} \\
M A E & = \pm \frac{1}{n} \sum_{i=1}\left|x_{i}-x_{j}\right|
\end{aligned}
$$

Where $x_{i}$ is the value of truth truthing points, $x_{j}$ is the value of truth truthing points. (Figure 5) shows the summary of the study methodology 


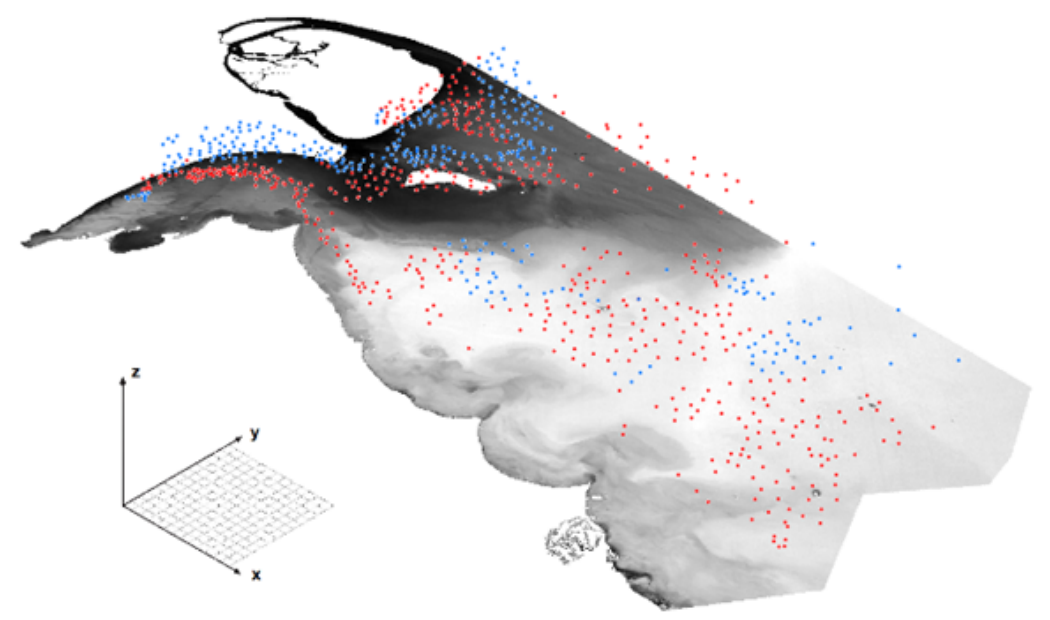

Fig. 4. The ground-truthing points were used to calibrate the Landsat 8 RTA derived model through regression analysis, and to evaluate the derived model from regression. Red points referred to those used to calibrate the model, while blue to those used to evaluate it.

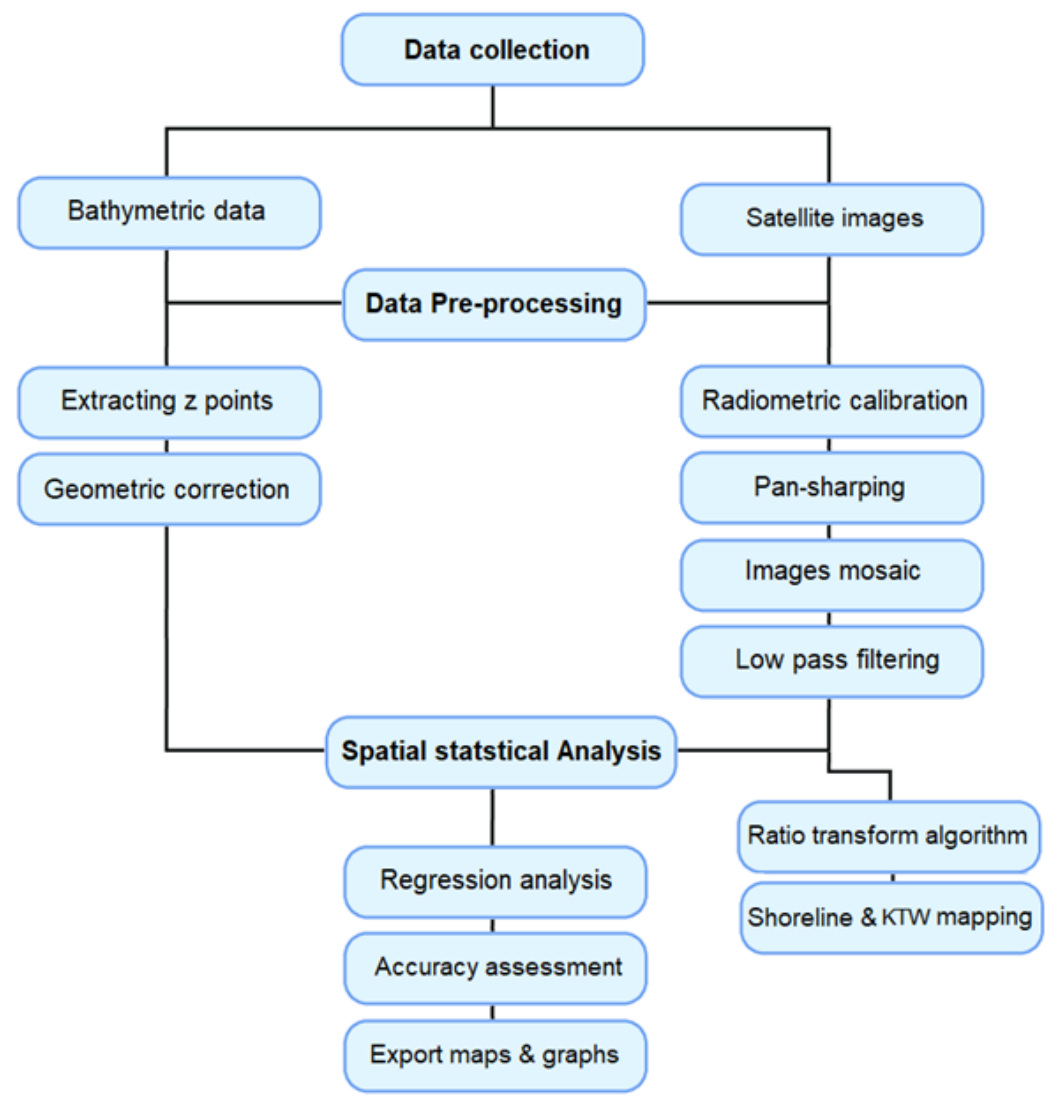

Fig. 5. Summary of the study methodology.

\section{Results}

The correlation was estimated and examined using GTPs, where the relation between the RTA and GTPs was strongly positive $\left(r^{2}=0.9634\right)$ (Figure 6). Statistical indices conclude RMSE and MAE were used for validation and they show strong accuracy of the derived final model, where they were $= \pm$ 1.66 and \pm 1.29 meters respectively (Table 1 ). The northern area was evaluated separately, due to the unique natural properties of the region, and its $\mathrm{r}^{2}$ value was found to be 0.386 (Figure 7).

The following formula was derived from regression analysis and it was used to estimate 
the depth of Kuwait water:

$$
Z=130.3(x)-128.13
$$

Where $\mathrm{Z}$ is the estimated depth, $x$ is the derived values from an optical satellite image.

The results showed that the depths increase from north to the southern regions, where the greatest depths are found. In addition, Kuwait Bay showed shallow depths, with exception of the southwestern entrance of the bay and the far western region (Figure 8). The average depth of Kuwaiti seawaters is 19.7 meters, with a standard deviation of about 9 meters from the mean, where the mode is roughly 26 meters (Figure 9).

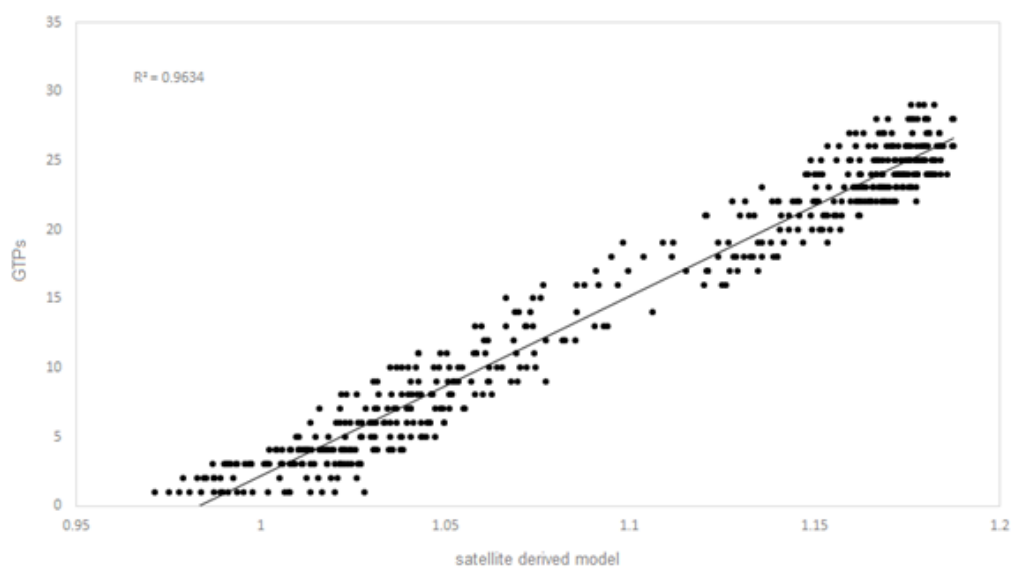

Fig. 6. The linear correlation between ground-truthing points and Landsat 8 RTA derived model. $(\mathrm{p}$-value $=0)$.

Table 1. $\mathrm{r}^{2}$, RMSE, and MAE scores.

\begin{tabular}{lccc}
\hline & $r^{2}$ & RMSE $(m)$ & MAE $(m)$ \\
\hline Ratio Transform Algorithm & 0.9634 & 1.66 & 1.29 \\
\hline
\end{tabular}

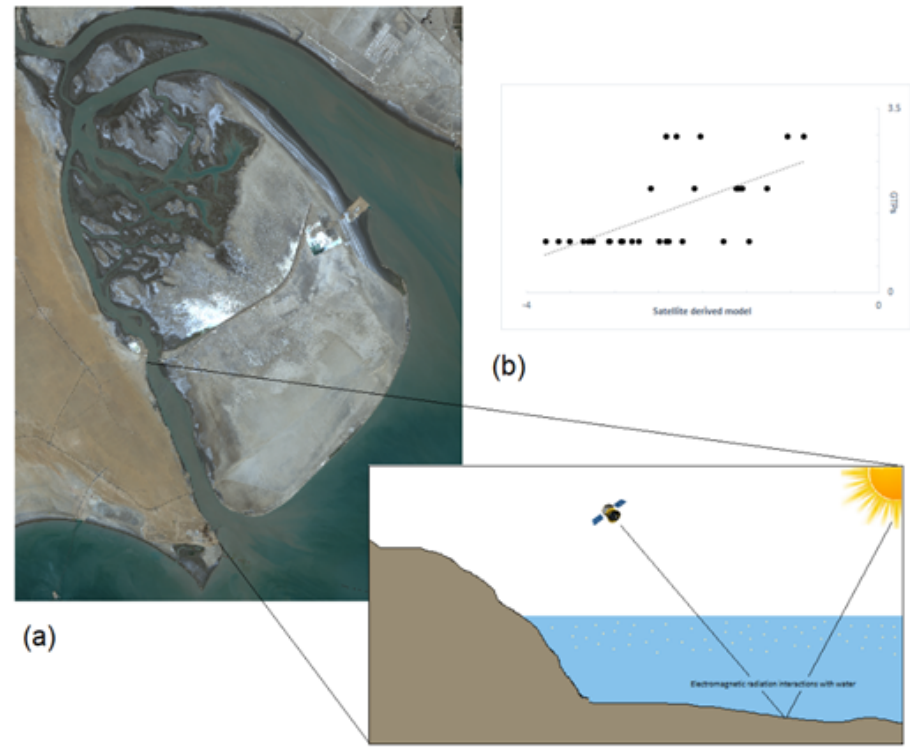

Fig. 7. High sediment concentration on the Northern Kuwait water affects the capacity of optical bands to estimate the depths (a). The correlation was estimated between the final 
bathymetric model and GTPs $(n=29)$ to be $0.386($ b). The image: Landsat 8 natural colour image captured on 6 July 2019.
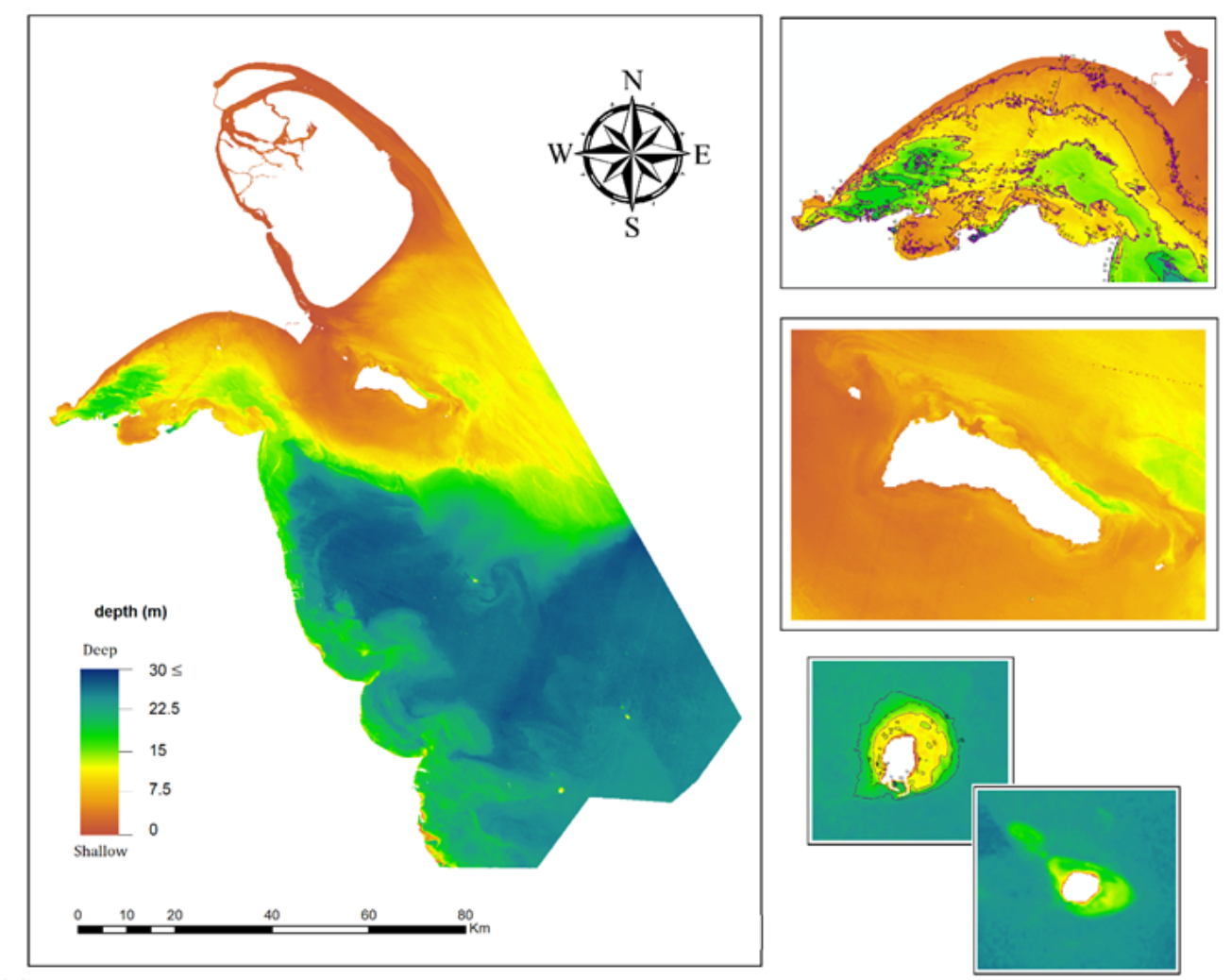

(a)

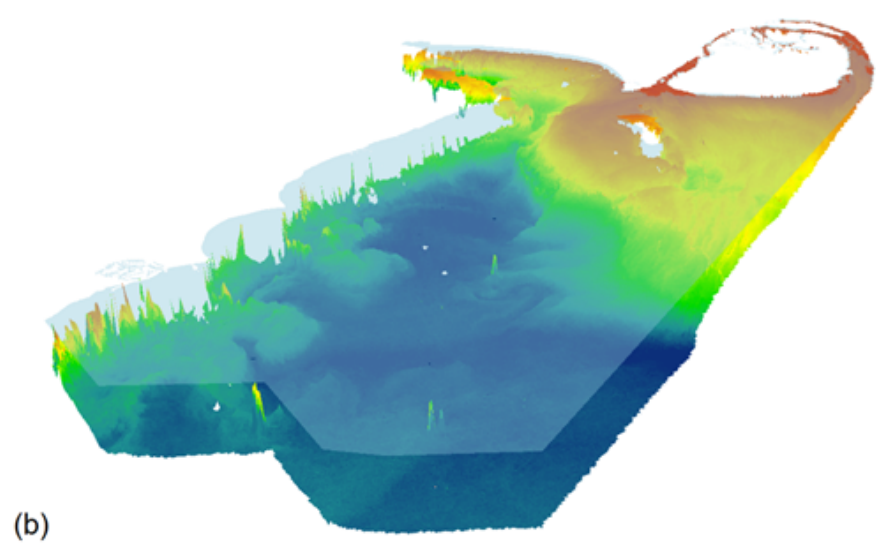

Fig. 8. The final model of Kuwait territorial water bathymetry in the form of $2 \mathrm{D}(\mathrm{a})$ and $3 \mathrm{D}$ maps (b). The detailed maps show Kuwait Bay, Failaka, Imm Al-Maradim, and Qaruh Islands. Contour lines are obtained in some detailed maps. 


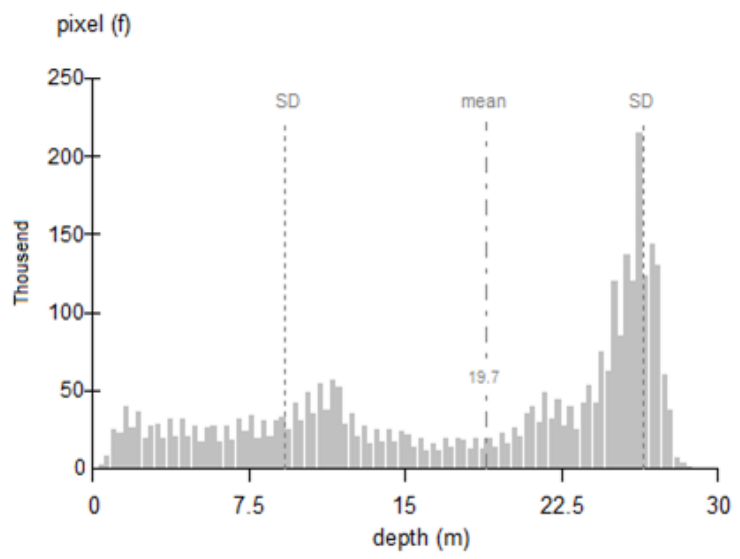

Fig. 9. The histogram shows the statistical distribution, mean, and SD values of Kuwait's territorial water bathymetry.

\section{Discussion and conclusion}

Passive remote sensing showed a good ability to estimate bathymetry using blue and green spectral bands. However, this method provides a model that covers each point in the water with a spatial resolution of 15 meters, which means that continuous data can be provided, and we can clearly explain the geographical distribution of seawater depths, unlike the prepared maps from the field survey which provide the depths in a shape of points; this gives us derived contour lines or the ability to form digital elevation models. The geographic distribution of the depths showed an observed similarity with the Ministries of Transportation (1986) and Defence (the 1990s) bathymetric maps of Kuwait. Despite the advantages of this method, the ability of the blue-green bands to penetrate the water column depends on the clarity and quality of the water, as turbid water gives early reflections. Based on the correlation result, the researcher's field survey of the northern region of Kuwait (around Bubyan Island) and Doha Bay (the west area of Kuwait Bay), it is noticed that the ability of multi-spectral remote sensing to extract the bathymetry for these areas is limited due to the water's turbidity, high sedimentary concentration, and bioactivity. Therefore, the depths may appear relatively low in these areas affected by reflection from sediment particles and dissolved organics. Further studies are needed to map the depths of the northern region, especially with the availability of remote sensing methods and geographic information system solutions.

Optical remote sensing shows a good ability to estimate depths using the ratio transform algorithm using Landsat 8 data. The correlation was estimated using GTPs, where the relationship was positive $\left(r^{2}=\right.$ 0.9634). Statistical measurements such as RMSE and MAE show the accuracy of the model, where they were $= \pm 1.66$ and \pm 1.29 meters respectively. The northern area was evaluated separately, due to the unique natural properties of the region, and its $r^{2}$ value was found to be 0.386 .

\section{ACKNOWLEDGMENTS}

The author would like to thank the Environmental Public Authority. Especially, eMISK, marine monitoring, and marine services sections. Also, acknowledgments must go to the USGS for the available satellite images of Landsat 8.

\section{References}

Al-salem, K., Neelamani, S., \& Al-nassar, W. (2018). Wind Energy Map of Arabian Gulf. Natural Resources, 9(5), 212-228. https://doi.org/10.4236/nr.2018.95014

Al Jassar, H. K., \& Rao, K. S. (2015). Assessment of soil moisture through field measurements and AMSR-E remote sensing 
data analysis over Kuwait desert. Kuwait Journal of Science, 42(2), 250-260.

Albanai, J. A. (2019). A GIS Science Simulation for the Expected Sea Level Rise Scenarios on Failka Island in The State of Kuwait (1st ed.). Kuwait: Center For Research and Studies on Kuwait.

Albanai, J. A. (2020). Sea Level Rise Projections for Failaka Island in The State of Kuwait. Transaction on Maritime Science, 9(2), 236 - 247. https://doi.org/10.7225/toms. v09.n02.008.

Alyamani, F., Bishop, J., Ramadhan, E., Al-Husaini, M., \& Al-Ghadban, A. (2004). Oceanographic Atlas of Kuwait's waters (1st ed.). KISR.

Carron, M. J., Vogt, P. R., \& Jung, W. (2001).

A Proposed International Long-term Project to Systematically Map the World's s Ocean Floors from Beach to Trench : GOMaP(Global Ocean Mapping Program). International Hydrographic Review, 2(3), 49-55.

El-Baz, F., \& Al-Sarawi, M. (2000). Atlas of State of Kuwait From Satellite Images (1st ed.). Kuwait Foundation for the Advancement of Sciences (KFAS).

Environment Public Authority. (2020). eMISK. Retrieved April 10, 2019, from epa. org.kw

Evagorou, E., Mettas, C., Agapiou, A., Themistocleous, K., \& Hadjimitsis, D. (2019). Bathymetric maps from multi-temporal analysis of Sentinel-2 data: the case study of Limassol, Cyprus. Advances in Geosciences, 45, 397-407.

Frazier, P. S., Frazier, P. S., Page, K. J., \& Page, K. J. (2000). Water Body Detection and Delineation with Landsat TM Data. Photogrammetric Engineering \& Remote Sensing, 66(12), 1461-1467. https://doi. org/0099-1112I0OI6612-1461\$3.00/0
Karbassi, A. R., Abdollahzadeh, E. M., Attaran-Fariman, G., Nazariha, M., \& Assadi, M. M. (2017). Predicting the distribution of harmful algal bloom ( HAB ) in the coastal area of Oman sea Nature Environment Predicting the Distribution of Harmful Algal Bloom ( HAB ) in the Coastal Area of Oman Sea. Nature Environment and Pollution Technology, 16(1), 753-764.

Lyzenga, D., Malinas, N. P., \& Tansi, F. J. (2006). Multispectral Bathymetry Using a Simple Physically Based Algorithm. IEEE Transactions on Geoscience and Remote Sensing, 44(8), 2251-2259. https://doi. org/10.1109/TGRS.2006.872909

Lyzenga, D. R. (1978). Passive remote sensing techniques for mapping water depth and bottom features. APPLIED OPTICS, 17(3), 379-383.

Lyzenga, D. R. (1985). International Journal of Remote Sensing Shallow-water bathymetry using combined lidar and passive multispectral scanner data. International Journal of Remote Sensing, 6(1), 115-125.

Philpot, W. D. (1998). Bathymetric mapping with passive multispectral imagery. APPLIED OPTICS, 28(8). https://doi. org/10.1364/AO.28.001569

Pushparaj, J., \& Hegde, A. V. (2017). Estimation of bathymetry along the coast of Mangaluru using Landsat-8 imagery. The International Journal of Ocean and Climate Systems, 8(2), 71-83. https://doi. org/10.1177/1759313116679672

Rezaei-latifi, A. (2015). ScienceDirect Variability of Fresnel surface emissivity of Persian Gulf water in a nadir-viewing direction at C- band. Journal of Radiation Research and Applied Sciences, 9(2), 131138. https://doi.org/10.1016/j.jrras.2015.10.004

Stumpf, R. P., \& Holderied, K. (2003). Determination of water depth with high- 
resolution satellite imagery over variable bottom types. American Society of Limnology and Oceanography, 48, 547-556.

USGS. (2020). Earth Explorer. Retrieved July 27, 2020, from earthexplorer.usgs.gov

Submitted: $\quad 09 / 01 / 2020$

Revised: $\quad 08 / 09 / 2020$

Accepted: $\quad 02 / 11 / 2020$

DOI: $\quad 10.48129 / \mathrm{kjs} . v 48 \mathrm{i} 4.8978$ 